
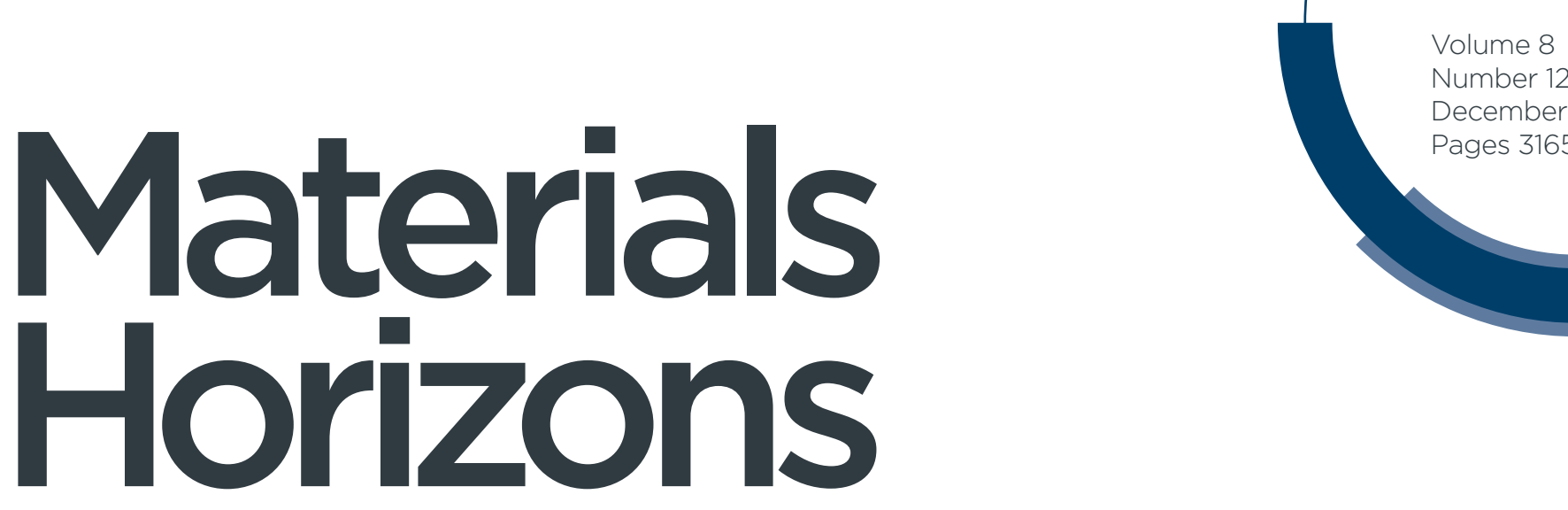

Number 12

December 2021

Pages 3165-3478

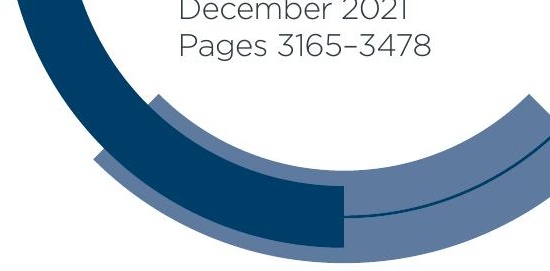

\title{
rsc.li/materials-horizons
}

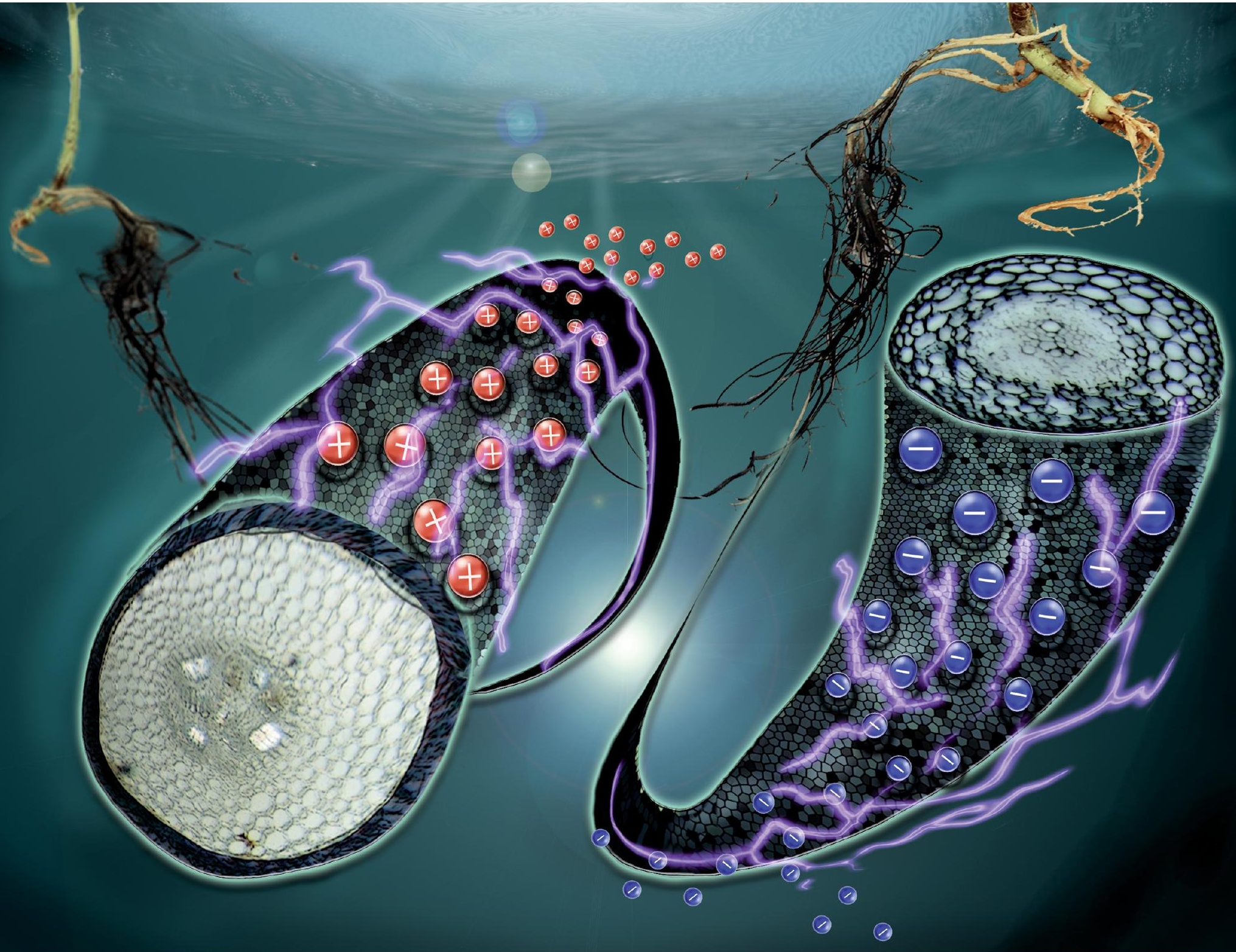

ISSN 2051-6347 
Check for updates

Cite this: Mater. Horiz., 2021, 8,3295

Received 2nd September 2021 Accepted 15th October 2021

DOI: $10.1039 / \mathrm{d} 1 \mathrm{mh} 01423 \mathrm{~d}$

rsc.li/materials-horizons

\section{Biohybrid plants with electronic roots via in vivo polymerization of conjugated oligomers $\dagger$}

\author{
Daniela Parker, ${ }^{a}$ Yohann Daguerre, ${ }^{b}$ Gwennaël Dufil, ${ }^{a}$ Daniele Mantione, (D) ${ }^{c}$ \\ Eduardo Solano, (D) d Eric Cloutet, ${ }^{c}$ Georges Hadziioannou, ${ }^{c}$ Torgny Näsholm, ${ }^{b}$ \\ Magnus Berggren, ${ }^{\text {ae }}$ Eleni Pavlopoulou (D) ${ }^{\dagger}$ and Eleni Stavrinidou (D) *abe
}

Plant processes, ranging from photosynthesis through production of biomaterials to environmental sensing and adaptation, can be used in technology via integration of functional materials and devices. Previously, plants with integrated organic electronic devices and circuits distributed in their vascular tissue and organs have been demonstrated. To circumvent biological barriers, and thereby access the internal tissue, plant cuttings were used, which resulted in biohybrids with limited lifetime and use. Here, we report intact plants with electronic functionality that continue to grow and develop enabling plant-biohybrid systems that fully maintain their biological processes. The biocatalytic machinery of the plant cell wall was leveraged to seamlessly integrate conductors with mixed ionic-electronic conductivity along the root system of the plants. Cell wall peroxidases catalyzed ETE-S polymerization while the plant tissue served as the template, organizing the polymer in a favorable manner. The conductivity of the resulting $p(E T E-S)$ roots reached the order of $10 \mathrm{~S} \mathrm{~cm}^{-1}$ and remained stable over the course of 4 weeks while the roots continued to grow. The $p(E T E-S)$ roots were used to build supercapacitors that outperform previous plantbiohybrid charge storage demonstrations. Plants were not affected by the electronic functionalization but adapted to this new hybrid state by developing a more complex root system. Biohybrid plants with electronic roots pave the way for autonomous systems with potential applications in energy, sensing and robotics.

\section{Introduction}

Biohybrid technologies aim to merge biological structures and processes with artificial systems to form advanced technological components. A great advantage of biohybrid approaches is that

\begin{abstract}
New concepts
In this work, we present biohybrid plants with an electronic root system. We demonstrate that by simply watering plants with a conjugated oligomer solution, the oligomers polymerize on the roots forming an extended network of easily accessible conductors. The plant's biocatalytic machinery drives the polymerization and templates the polymer along its tissue. The integrated mixed ionic-electronic conductors maintain their functionality over weeks and as a proof of concept we demonstrate energy storage. While previous examples of electronic functionalization of plants focused on plant cuttings, in this work, we functionalized intact plants that maintain their biological functions and continue to grow and develop. Plants were not affected by the electronic functionalization but adapted to this new hybrid state by developing a more complex root system. Furthermore, we augment electronic functionality to the root system that it is highly responsive and adaptive to its environment and therefore promising for a broad range of biohybrid applications. The implications of the work go beyond biohybrid systems. This work contributes to advancing bio-fabrication - using a biological organism to fabricate functional materials/composites, to further understanding of biological tissue - artificial material interaction and broadly for the development of communication pathways between electronics and biology in a seamless manner.
\end{abstract}

they harness natural processes that have been optimized via millions of years of evolution while biomimetic systems are fully artificial. $^{1,2}$ Over the last decade there has been a growing interest in developing plant-based biohybrid technological systems by integrating smart materials and devices into plant structures. $^{3-5}$ Plants, from a technological perspective, are already amazing machineries. Plants are solar-powered and carbon negative - converting $\mathrm{CO}_{2}$ to chemical energy, they sense and adapt to various environmental stimuli, and they can

\footnotetext{
${ }^{a}$ Laboratory of Organic Electronics, Department of Science and Technology, Linköping University, SE-60174, Norrköping, Sweden. E-mail: eleni.stavrinidou@liu.se

${ }^{b}$ Umeå Plant Science Centre, Department of Forest Genetics and Plant Physiology, Swedish University of Agricultural Sciences, SE 90183 Umea, Sweden

${ }^{c}$ Université de Bordeaux, Bordeaux INP, CNRS, LCPO UMR 5629, F-33615, Pessac, France

${ }^{d}$ NCD-SWEET Beamline, ALBA Synchrotron Light Source, Carrer de la Llum 2-26, 08290 Cerdanyola del Vallès, Spain

${ }^{e}$ Wallenberg Wood Science Center, Linköping University, SE-60174, Norrköping, Sweden

${ }^{f}$ Institute of Electronic Structure and Laser, Foundation for Research and Technology-Hellas, P.O. Box 1527, 71110 Heraklion Crete, Greece

$\dagger$ Electronic supplementary information (ESI) available. See DOI: 10.1039/d1mh01423d
} 
self-repair via tissue regeneration. At the same time, they produce several useful materials, with cellulose being the most abundant biopolymer on Earth. Hence, plants offer a broad range of processes that can be leveraged for technological purposes.

In plant nanobionics approaches, for example, smart nanomaterials enable device functionality in plants. The nanoparticles are introduced to the plants where they spontaneously localize within specific plant tissues depending on their size and charge reaching even organelles such as chloroplasts. ${ }^{6,7}$ Strano's group developed plant nanobionic environmental sensors for nitroaromatic compounds ${ }^{8}$ and arsenite ${ }^{9}$ detection. Modified carbon nanotubes infiltrated in the plant leaves produced a readable signal when the plant took up the analyte of interest from the soil. Nanoparticles were also used as carriers of chemiluminescent reactants within the plant tissues, therefore rendering the plant light emitting. ${ }^{10}$

We have merged plants with conjugated polymers and introduced the concept of Electronic Plants where circuits and electrochemical devices are integrated into the plant structure. ${ }^{4,11}$ Conjugated polymers are very promising materials for biohybrid systems as they support mixed ionic-electronic conduction and therefore can act as transducers between biology and electronics. ${ }^{12,13}$ Their molecular structure can be tailored to react specifically with biological moieties while being solution processable enables them to take various shapes including a free standing form. ${ }^{14-16}$ By harnessing the physicochemical environment and compartmentalized tissues of the plant we demonstrated that PEDOT (poly(3,4-ethylenedioxythiophene)) polymers can self-organize in the xylem tissue and leaf apoplast and can be used as active layers for transistors and electrochromic pixels, respectively. ${ }^{4}$ The distribution of the polymers though within the plant was limited close to the side of infusion. Therefore, in a later work, we developed a conjugated trimer (ETE-S, bis[3,4-ethylenedioxythiophene]-3-thiophene butyric acid, sodium salt) that could flow through the plant's vasculature and at the same time polymerize in vivo without any external chemical or physical stimuli. ${ }^{11}$ Recently, we found that cell wall peroxidases, activated by endogenous hydrogen peroxide, are responsible for the ETE-S polymerization. ${ }^{17}$ Plants therefore have the biocatalytic machinery to polymerize in vivo conjugated oligomers and integrate the resulting conducting polymers within their cell walls. ${ }^{17,18}$ However, in our previous studies we used plant cuttings and not intact plants limiting the lifetime of the biohybrid devices.

In this work, we report electronic functionalization of intact plants via in vivo polymerization of conjugated polymers for the long term integration of electronics into the plant structure. We focused on the root system of the plants as it responds to various chemical and physical stimuli, regulates the uptake of molecules from the growth environment and secretes numerous organic molecules and therefore is attractive for the development of energy devices and underground sensors. ${ }^{19-22}$ We demonstrate that by simply watering the plant with the conjugated oligomer solution, the oligomers polymerize on the roots forming an extended network of easily accessible mixed ionic-electronic conductors while the plant continues to grow and develop.

\section{Results and discussion}

Roots do not have a cuticle and therefore the epidermal cells and cell wall machinery are directly exposed to conjugated trimers for in vivo polymerization. Roots of young bean plants were thus immersed in a freshly prepared aqueous solution of the conjugated trimer, ETE-S $\left(1 \mathrm{mg} \mathrm{ml}^{-1}\right)$ (Fig. 1A). The rest of the root system was kept in a nutrient rich solution. Over time, we observed a dark coating on the roots indicating polymer formation. The polymerization was confirmed using UV-VIS spectroscopy on the root extracts where the characteristic peak of $\mathrm{p}(\mathrm{ETE}-\mathrm{S})$ was observed (Fig. S1, ESI $\dagger^{11,23}$ ). To reveal the polymerization kinetics on the roots, we performed time lapse microscopy and monitored in situ the polymer formation (Fig. S2, ESI $\dagger$ ). Selected images are presented in Fig. 1B. Within the first $60 \mathrm{~min}$, no significant color change was obvious on the surface of the roots, indicating very little polymerization. As time went by, the roots became darker with the polymer forming on the epidermal cells; after $300 \mathrm{~min}$, the roots were covered by the polymer. To get further insights on the kinetics, we quantified at selected time points the root color change corresponding to the polymer amount on the root surface (Fig. S3, ESI $\dagger$ ). The polymer amount increased over time following a sigmodal behavior with initial slow kinetics, then faster kinetics, followed by saturation to $90 \%$ (Fig. 1C, Fig. S4, ESI $\dagger$ ). The sigmoidal behavior can be explained by the polymerization mechanism of ETE-S in plants. As previously shown, ETE-S polymerizes enzymatically due to the activity of cell wall peroxidases in the presence of endogenous $\mathrm{H}_{2} \mathrm{O}_{2} \cdot{ }^{17}$ Initially, the polymerization is slow because it is limited by the diffusion of ETE-S to the root surface and within the cell walls. When the ETE-S molecules react with peroxidases they will oxidize and when two ETE-S radicals combine, dimers will form. Longer oligomers will also form by the radical transfer from ETE-S radicals to ETE-S dimers and so on. Therefore, after the initial slow polymerization, faster kinetics were observed at a linear speed of $0.34 \% \mathrm{~min}^{-1}$ due to the formation of sufficient nucleation sites or ETE-S radicals. At the last phase, we observed saturation of the polymer coating and the half time of the polymerization reaction was found to be $152 \mathrm{~min}$. Although the polymerization process can continue beyond 350 min, enabling the coating to become thicker, this could not be observed using microscopy analysis as the root became too opaque to reveal any further changes in color, explaining the saturation phase.

After evaluating the initial ETE-S polymerization kinetics on the roots, we functionalized the plant for three days and characterized in more detail the polymer localization on the roots (Fig. 2). Roots are generally sub-divided into three main developmental zones, Fig. $2 \mathrm{~A}^{24,25}$ The meristematic area is the site of active cell division from which the root cap or the functional root originates depending on the direction of the division. In the elongation area, cells undergo a very rapid elongation, propelling the roots through the soil. At this stage, the endodermis, casparian strip and early vessel elements start to differentiate. In the maturation area, vessels fully differentiate 

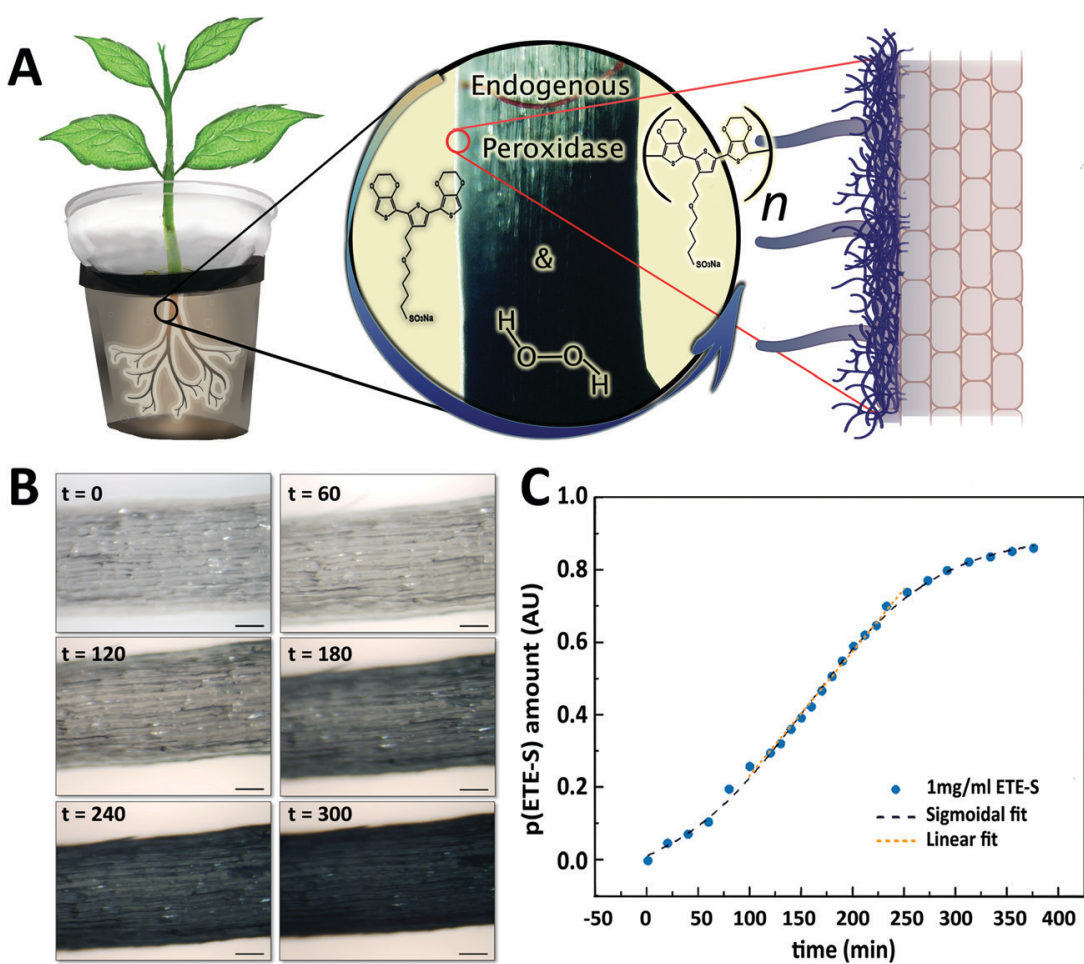

Fig. 1 Electronic functionalization of plant roots (A) ETE-S polymerizes on the roots of intact bean plant catalyzed by endogenous plant cell wall peroxidases and $\mathrm{H}_{2} \mathrm{O}_{2}$. (B) Micrographs of the root during ETE-S polymerization at different time points from the onset of the reaction (timescale: minutes, scalebar: $100 \mu \mathrm{m})$. (C) Temporal evolution of $\mathrm{p}(\mathrm{ETE}-\mathrm{S})$ amount on the root.

while root hairs and lateral roots might start to appear. In order to study in detail the polymer deposition on the root depending on the developmental zones, images were taken at different distances from the root tip. Representative plane view images and cross-sections of the meristematic-elongation and maturation zones are shown in Fig. 2B, C and D, respectively. From the plane view images, we can observe a homogeneous and abundant coating along the root, with the exception of the root tip area where the coating is sparse and heterogeneous as exemplified in Fig. 2B. The cross-section images, both longitudinal and transversal, showed that the polymer localized only on the epidermis/exodermis cell layers of the root and this was independent of the root developmental stages. Although, as previously demonstrated, internal tissue from plants such as xylem or pith cells have the machinery to polymerize ETE-S, ${ }^{11,17}$ ETE-S did neither reached nor polymerized within the internal structure of the intact roots. In some cases, when roots were wounded, we observed polymerization of ETE-S in the internal tissue (Fig. S5, ESI $\dagger$ ), but these were isolated observations and never happened in healthy roots. Roots must regulate the uptake of molecules from the soil to the vascular tissue in order to ensure proper nutrient exchange and restrict the uptake of harmful elements. For this, plants have developed different physiological barriers such as the exodermis and the endodermis. The exodermis is located right below the epidermis and is characterized by a Casparian strip, suberin deposition and additional cell wall modification, modulating root permeability depending on its environment. ${ }^{26,27}$ Our results bring evidence that ETE-S does not pass beyond this first barrier. At the root tip, the epidermal/ exodermal cell layers are not yet differentiated, and the root apex is protected by a root cap. A recent study has demonstrated in Arabidopsis that the root cap first cell layer of 2-3 days old seedling possesses a cuticle similar to the one observed in the shoot. ${ }^{28}$ However, this protective layer is later replaced by a permanent renewal of the cells, with the outer layer being eliminated..$^{29,30}$ In addition, a mature root cap secretes a mucilage composed of cell wall polysaccharides and proteins acting as lubricants while the root is prospecting the soil. ${ }^{31,32}$ These protective mechanisms could explain the heterogeneous deposition of the coating observed in the root tip area and why ETE-S has not entered the internal structure of the root via the root tip. Despite the presence of the coating, the root tissue looked healthy without any obvious damage due to polymerization such as structural disorganization or deformation of the tissue. From the images shown in Fig. 2D, it can be observed that the polymer is forming a coating on the plant cell walls as individual cells acquire blue coloration (indicated by red arrows). In some cases, the emergence of lateral roots is obvious as shown in Fig. 2C and D. Next, we investigated if the concentration of ETE-S affected the coating and its localization by functionalizing the plant root with $2 \mathrm{mg} \mathrm{ml} \mathrm{ml}^{-1}$ ETE-S (Fig. S6, ESI $\dagger$ ). As before, plant root's main structure was preserved, and the polymer deposited essentially on the epidermis/exodermis cell layers of the root. Root hairs that were present in the maturation zone of these root samples were also coated with the polymer as illustrated in Fig S7 (ESI $\dagger$ ). However, in some cases the coating 

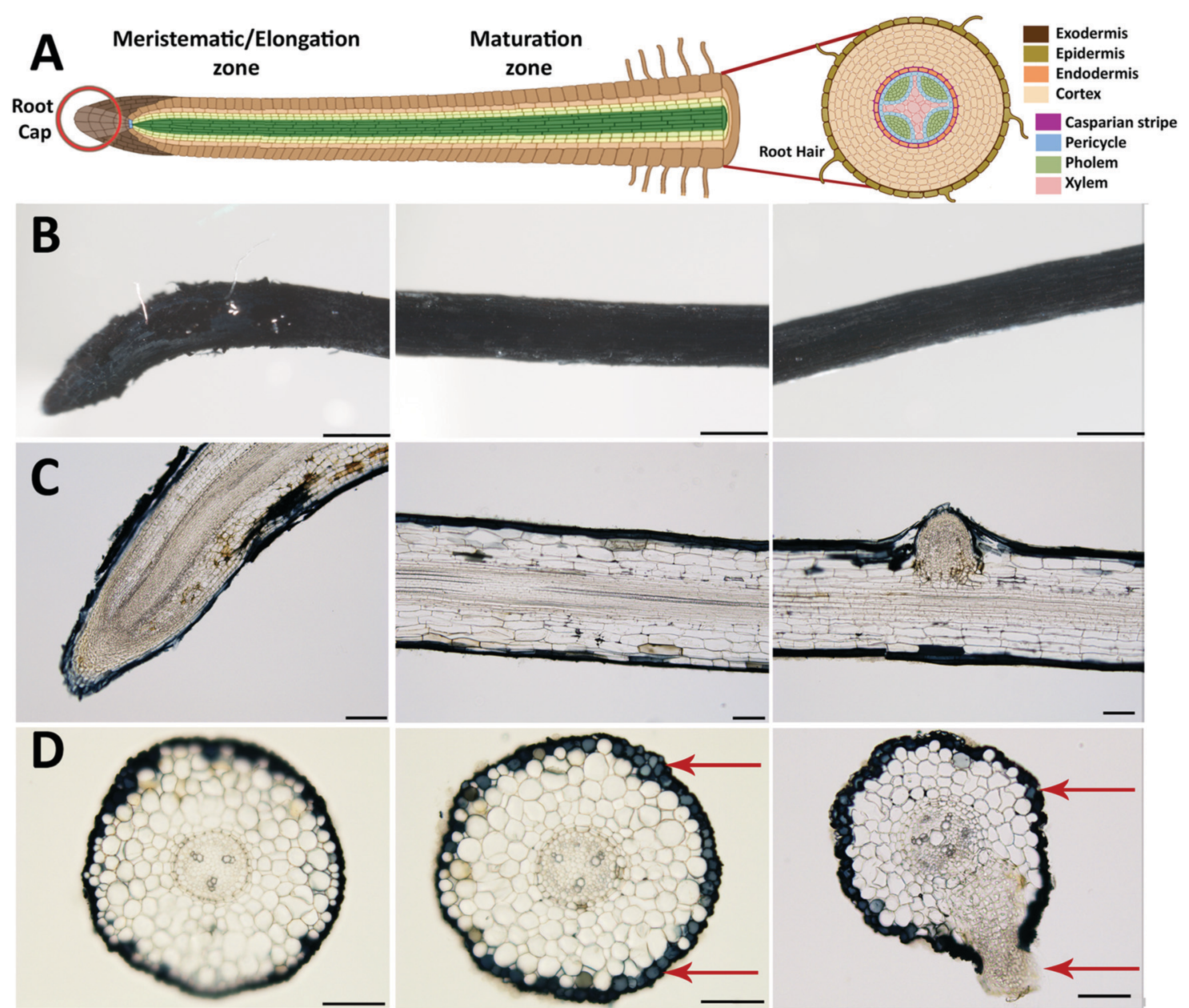

Fig. 2 Root functionalized with $1 \mathrm{mg} \mathrm{ml}^{-1}$ of ETE-S for 3 days. (A) Schematic of the root anatomy indicating the various tissues and developmental zones (created with BioRender.com). p(ETE-S) fixed root micrographs for (B) plane views (scalebar $500 \mu \mathrm{m}$ ) (C) longitudinal cross-sections, (scalebar $100 \mu \mathrm{m}$ ) and (D) transversal cross-sections (scalebar $100 \mu \mathrm{m}$ ). In (B-D) the first column corresponds to the meristematic-elongation zone while second and third columns correspond to the maturation zone of the root.

was detaching from the root and in some cases the epidermal cell layer was peeling off, which could be explained by an increase in the rigidity of the plant cell walls due to a higher deposition and concentration of ETE-S. In the root tip area particularly, the coating is thicker and more granulated than in the case of $1 \mathrm{mg} \mathrm{ml}^{-1}$ - ETE-S functionalized roots. At the root cap area, a dense coating is observed even extending beyond the root tissue reaching the root tip hydrogel (root secretions). Several fully coated cell layers from the root cap were released from the root tip Fig. S6 (ESI $\dagger)$. The renewal of the root cap cell layers is a natural process involved in root mucilage secretion and plant response to biotic and abiotic stresses. ${ }^{33}$ ETE-S may have triggered an accelerated renewal of this cell layer; however, more experiments are needed to test this hypothesis. Overall, the integrity of the root tip and the meristematic area were preserved.

The electrical properties of the roots functionalized with $1 \mathrm{mg} \mathrm{ml}^{-1}$ and $2 \mathrm{mg} \mathrm{ml}^{-1}$ ETE-S solutions were characterized using current-voltage $(I-V)$ measurements at various interelectrode distances, Fig. 3A and B. Because of the soft nature of the roots and coating we developed a set up enabling us to probe the functionalized root without applying large pressure or damaging the coating or the root tissue as described in the methods. The functionalized roots exhibited linear current-voltage dependance without hysteresis and increased resistance with distance which is typical of an ideal resistor behavior. For non-functionalized roots the recorded current was the same as the electrolytic contribution as shown in Fig. S8 (ESI $\dagger$ ). To calculate the resistivity, we measured the coating cross section area from the micrographs of the samples characterized. For $1 \mathrm{mg} \mathrm{ml}^{-1}$ and $2 \mathrm{mg} \mathrm{ml}^{-1}$ ETE-S concentrations, the average areas were $5 \times 10^{-5} \mathrm{~cm}^{2}$ and $5.8 \times 10^{-5} \mathrm{~cm}^{2}$, respectively. We observed an increase in the average area of the coating of the roots functionalized with $2 \mathrm{mg} \mathrm{ml}^{-1}$ indicating that more material was deposited but not in a linearly proportional manner, in agreement with our previous characterization of the fixed samples. Conductivity of p(ETE-S) was calculated assuming an ideal resistor and was found equal to $12.4 \pm 6.1 \mathrm{~S} \mathrm{~cm}^{-1}$ and $5.5 \pm$ $1.8 \mathrm{~S} \mathrm{~cm}^{-1}$ for roots functionalized with $1 \mathrm{mg} \mathrm{ml}^{-1}$ and $2 \mathrm{mg} \mathrm{ml}^{-1}$, respectively, Fig. 3C. The conductivity tended to be higher for roots functionalized with $1 \mathrm{mg} \mathrm{ml}{ }^{-1}$ ETE-S but the difference was not 

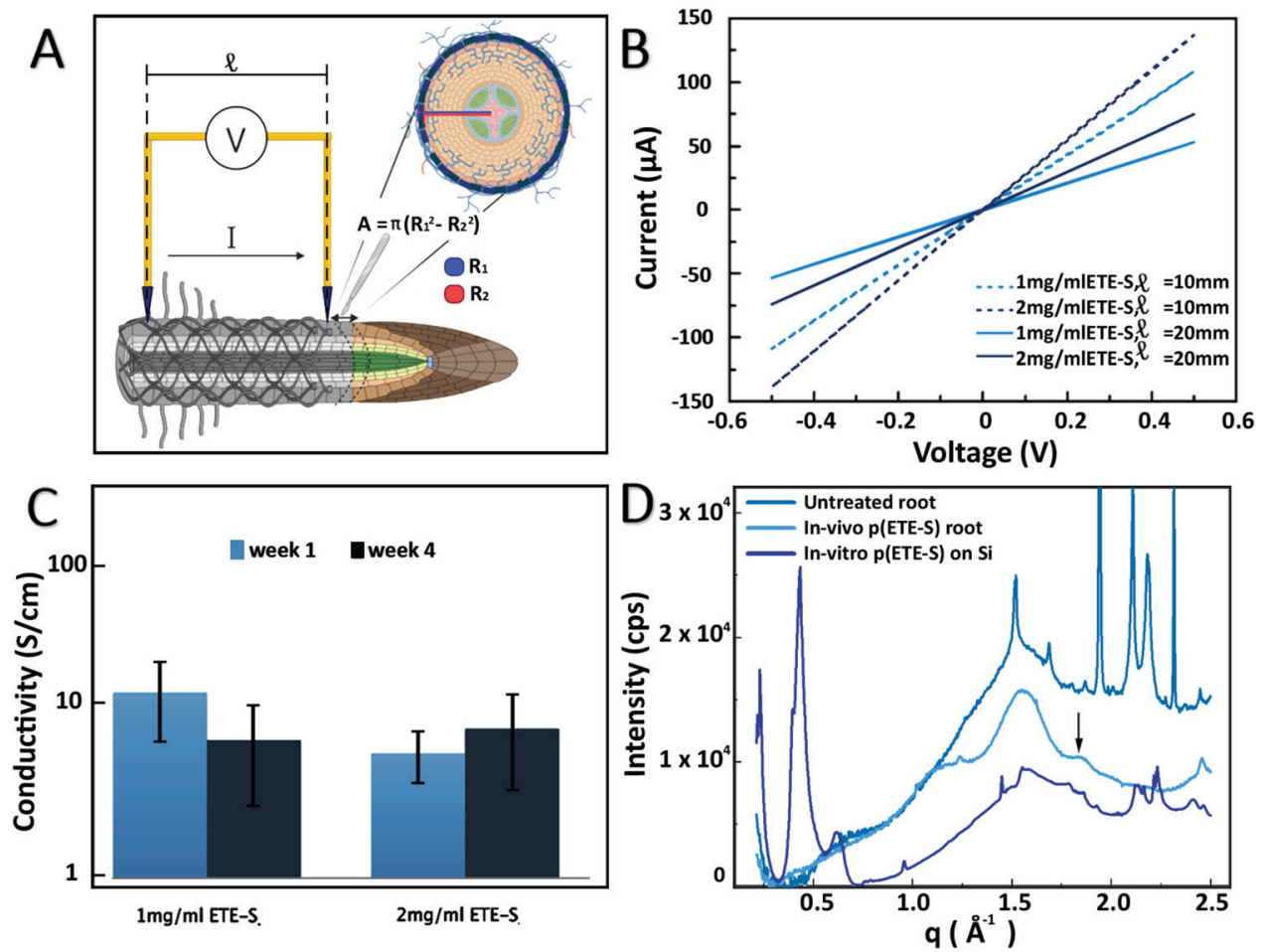

Fig. 3 Electrical and structural characterization of $\mathrm{p}(\mathrm{ETE}-\mathrm{S})$ functionalized roots. (A) Schematic of $I V$ measurements and conducting layer cross section determination (created with BioRender.com). (B) Current-voltage curves of $\mathrm{p}(\mathrm{ETE}-\mathrm{S})$ roots functionalized with 1 or $2 \mathrm{mg}^{\mathrm{ml}} \mathrm{l}^{-1} \mathrm{ETE}-\mathrm{S}$ and for interelectrode distances of $10 \mathrm{~mm}$ and $20 \mathrm{~mm}$. (C) Average conductivity of $p(E T E-S)$ roots 1 and 4 weeks after functionalization ( $n=3$ for each ETE-S concentration) while they remained attached to a growing plant. (D) Scattering profile of control root, $p(E T E-S)$ functionalized root and $p(E T E-S)$ film on Si.

significant due to variations among the samples. Next, we evaluated the stability of the conducting layer and how it changed while the functionalized roots were growing. We performed the analysis described above after four weeks from the day of functionalization. During this period, the characterized roots remained attached to the plant and the root system was incubated in a nutrient solution. Surprisingly, we did not observe significant changes in conductivity for either of the concentrations. For root functionalized with $1 \mathrm{mg} \mathrm{ml} \mathrm{m}^{-1}$ we observed a small decrease in conductivity while for roots functionalized with $2 \mathrm{mg} \mathrm{ml}^{-1}$ a small increase was observed but with no statistical differences in either case. Our results indicate that the $\mathrm{p}(\mathrm{ETE}-\mathrm{S})$ coating is stable in a nutrient rich solution and retains its conductivity after 4 weeks while the plant is growing. When conducting polymers are used as active materials in bioelectronic devices, they are usually crosslinked before exposure to the biological medium, for better stability. ${ }^{34}$ In contrast $\mathrm{p}$ (ETE-S) showed strong adhesion to the plant tissue with stable electrical properties without the need for any further processing or additives. We speculated that this was the result of the in vivo polymerization and templating of the conducting polymer directly to the plant structure.

To get further insights on the organization and structure of the polymer on the roots, we performed wide-angle X-ray scattering. The patterns recorded for a bare root and a p(ETES)-functionalized root are presented in Fig. 3D. The root pattern exhibited a broad peak centered at $1.55 \AA^{-1}$ which was assigned to cellulose ${ }^{35}$ and demonstrates its disordered arrangement in the root tissue. After functionalization, a new peak was observed at $1.85 \AA^{-1}$, characteristic of the $\pi-\pi$ stacking of thiophene rings with a stacking distance of $3.4 \AA$ A. This feature was attributed to the organization of the polymerized p(ETE-S) chains along the 010 direction, consistent with the crystalline structure of PEDOT. ${ }^{36}$ This peak was observed for both studied ETE-S concentrations, 1 and $2 \mathrm{mg} \mathrm{ml} \mathrm{ml}^{-1}$. In order to reveal the effect of the root on the organization of $\mathrm{p}$ (ETE-S), we enzymatically polymerized ETE-S in vitro by mixing ETE-S, horse radish peroxidase and $\mathrm{H}_{2} \mathrm{O}_{2}$. The obtained polymer solution was then drop casted on a Si substrate. The scattering pattern of this film presented two striking differences with respect to root samples. Intense peaks arose at $0.22,0.43$ and $0.63 \AA^{-1}$, corresponding to the $h 00$ reflections generated by the lamella stacking of polymerized ETE-S along its aliphatic side chain direction. ${ }^{37}$ This ordering was induced by the confinement of the thin polymeric film on its substrate (herein, silicon). ${ }^{37}$ The broad peak observed around $1.65 \AA^{-1}$ was related to the $\pi-\pi$ stacking arrangement of the trimers. However, the large width of this peak was characteristic of a lower degree of order, i.e. of a lack of a long-range order. Remarkably, this was not the case for the in vivo polymerized trimer on the root, where the $\pi-\pi$ peak was much narrower and centered at a higher $q$ value. This suggested that $\pi-\pi$ stacking was more compact with a smaller stacking distance. The $\pi-\pi$ stacks were better ordered with a higher long-range order in vivo compared to in vitro. This comparison reveals that the plant tissue acts as a 
template for the polymerization of p(ETE-S) and drives the spatial organization of the polymer, resulting in a better ordering along the $\pi-\pi$ direction.

The conductivity measurements showed that ETE-S when polymerized on the roots was conducting and hence doped. The sulfonate side chain acts as a dopant that compensates the positive charges on the polymer backbone making p(ETE-S) a self-doped conjugated polymer. ${ }^{38}$ As the sulfonate side chain facilitates the transport of ions, $\mathrm{p}$ (ETE-S) is also a mixed conductor capable of transporting both electronic and ionic carriers in a coupled manner. Therefore, p(ETE-S) functionalized roots can be used as active materials in electrochemical devices integrated within the plant. We characterized the electrochemical properties of the roots by cyclic voltammetry (CV). The functionalized root was used as the working electrode in a 3-electrode electrochemical set up with carbon felt as the counter electrode and $\mathrm{Ag} / \mathrm{AgCl}$ as the reference electrode, Fig. 4A. A typical CV curve of the ETE-S functionalized root is shown in Fig. 4B. We observed that the root was further doped (oxidized) and dedoped (reduced) within a potential window of $(-0.5 \mathrm{~V}$, $+0.5 \mathrm{~V}$ ). The $\mathrm{CV}$ had a box shape, ranging between $-0.1 \mathrm{~V}$ and $+0.5 \mathrm{~V}$, indicating that doping was based on electrostatic processes and not faradaic; anions from the electrolyte compensated the injected charges on the polymer backbone as in the case of PEDOT. ${ }^{23,39}$ At lower potentials the root became resistive as it was being dedoped (reduced). By performing CV at different scan rates, we observed that the current plateau increases linearly with scan rates at 5 and $10 \mathrm{mV} \mathrm{s}^{-1}$ confirming the capacitive nature of the charging. With increasing scan rates, we observed a larger deviation from the box shape. Typically, the electrochemical properties of conjugated polymers are assessed by depositing the film on a conducting substrate, so the system is not limited by lateral electronic transport. In the case of $\mathrm{p}$ (ETE-S) functionalized root, the electrochemical properties of $\mathrm{p}$ (ETE-S) were characterized using the plant root as the substrate which is only ionically conducting. Therefore, the deviation from the box shape at higher scan rates may be a result of the ionic or even electronic transport limitation. However, even though electrical contact was made at a single point on the root, our measurements indicated that we could electrochemically address material several $\mathrm{mm}$ away from the contact point.

Next, we explored the possibility of using the roots for energy storage and building a root-based supercapacitor, Fig. 4C. Supercapacitors based on conducting polymers and cellulose offer an environmentally friendly alternative for energy storage that can be inexpensive and scalable. ${ }^{40,41}$ Furthermore, there is a growing interest for structural supercapacitors where the volume of an object can contribute to the charge storage. ${ }^{42,43}$ To this end, we constructed a proof-of-concept supercapacitor where the roots served as the charge storage electrodes. The cyclic voltammogram had a box shape that deviated from the ideal shape with increasing scan rate as observed in the
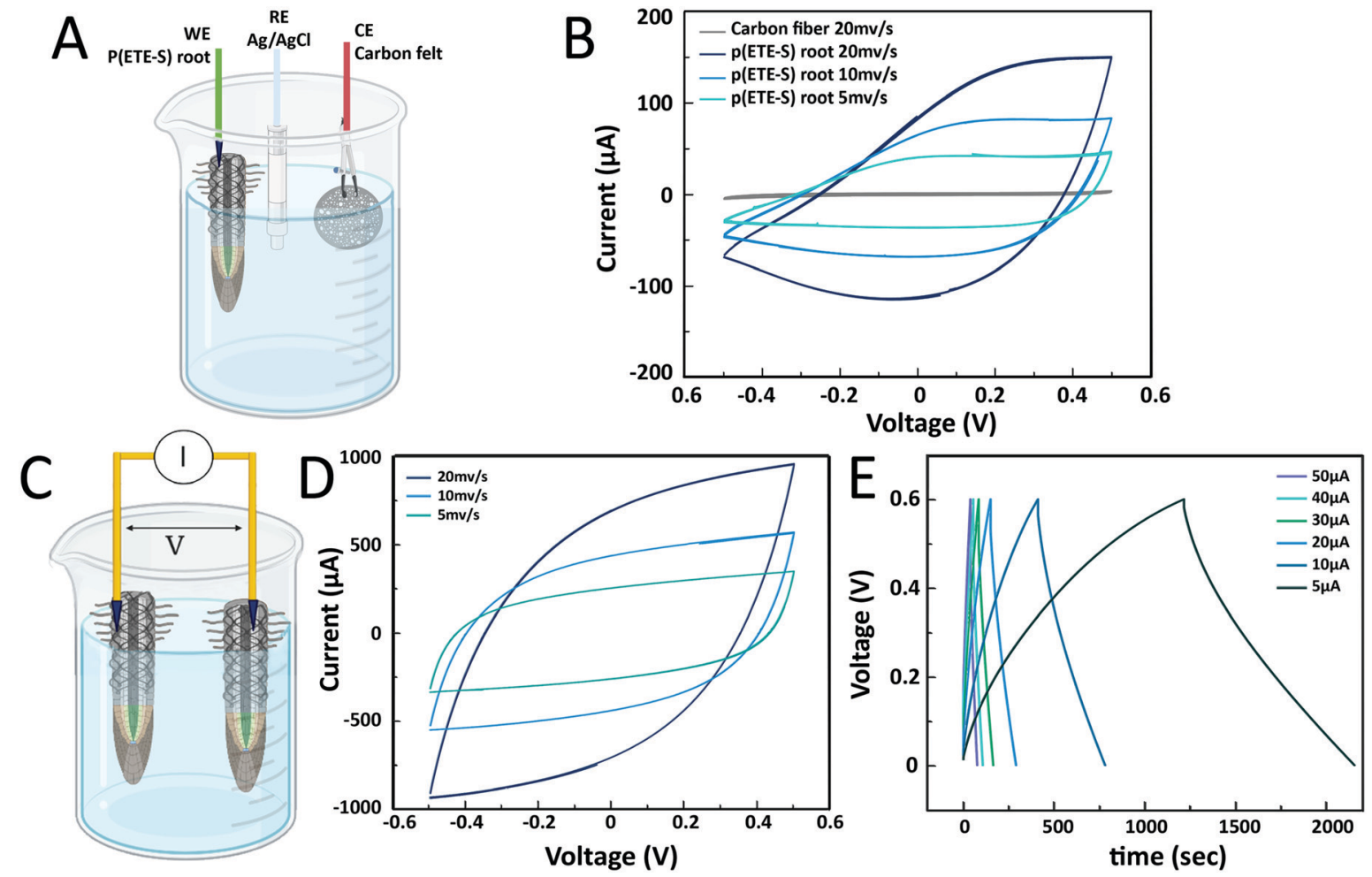

Fig. 4 Electrochemical properties of p(ETE-S) root and root-supercapacitor. (A) Schematic of the 3-electrode set-up used for the cyclic voltammetry of the $p(E T E-S)$ root (created with BioRender.com). (B) Typical cyclic voltammogram of the p(ETE-S) root at 5, 10 and $20 \mathrm{mV} \mathrm{s} \mathrm{s}^{-1} \mathrm{scan}$ rates. (C) p(ETE-S) root-supercapacitor schematic (created with BioRender.com). (D) Cycling voltammogram of the root-supercapacitor at scan rates of 5 , 10 and $20 \mathrm{mV} \mathrm{s}^{-1}$. (E) Galvanostatic charge-discharge curves at applied currents of 5, 10, 20, 30, 40, and $50 \mu \mathrm{A}$. 
$\mathrm{p}$ (ETE-S) root, indicating limiting ionic or electronic transport. ${ }^{44}$ The shape was symmetrical, between $+0.5 \mathrm{~V}$ and $-0.5 \mathrm{~V}$, signifying that the roots behaved as symmetrical electrodes. To calculate the capacitance of the rootsupercapacitor, we performed galvanostatic charging-discharging as most supercapacitors are operated in the constant current mode. The capacitance was $8 \mathrm{mF}$ for $5 \mu \mathrm{A}$ and decreased with increasing applied current reaching $4 \mathrm{mF}$ for $50 \mu \mathrm{A}$, Table $\mathrm{S} 1$ (ESI $\dagger$ ). The ESR (equivalent series resistance) was found to be between 1.3 and $1.8 \mathrm{k} \Omega$, signifying the potential drop between $\mathrm{p}$ (ETE-S) and the electrical contact point. Previously, we reported a supercapacitor based on $\mathrm{p}$ (ETE-S) wires in the xylem vascular tissue of the plant. The typical xylem-supercapacitor had capacitance of $0.07 \mathrm{mF}$ for $0.5 \mu \mathrm{A}$, ESR of $33 \mathrm{kOhm}$ and cut-off voltage at $0.25 \mathrm{~V}$. In the root-supercapacitor, we achieved 100 times higher capacitance with 10 times higher current and with more than double the cut-off voltage. Furthermore, the functionalized roots are readily accessible for external electrical contact, therefore represent a very promising avenue for building energy systems integrated in plants.

Plants with integrated conductors for potential use in energy systems or sensing will not only require stability of the electronic components but the plant should also remain healthy after functionalization. Therefore, we characterized root development and plant growth after functionalization. First, we functionalized the tap root (main root) of young seedlings with ETE-S (Fig. 5). The tap roots were coated with $\mathrm{p}$ (ETE-S) and no obvious difference was observed in terms of polymer coating, in comparison with the older roots that were functionalized in the previously discussed experiments (Fig. 1 and 2). However, in order to fully investigate if the polymerization efficiency and kinetics depend on the developmental stage of the plant, a systematic study is needed which will be the scope of another work. Then, we monitored the seedling growth

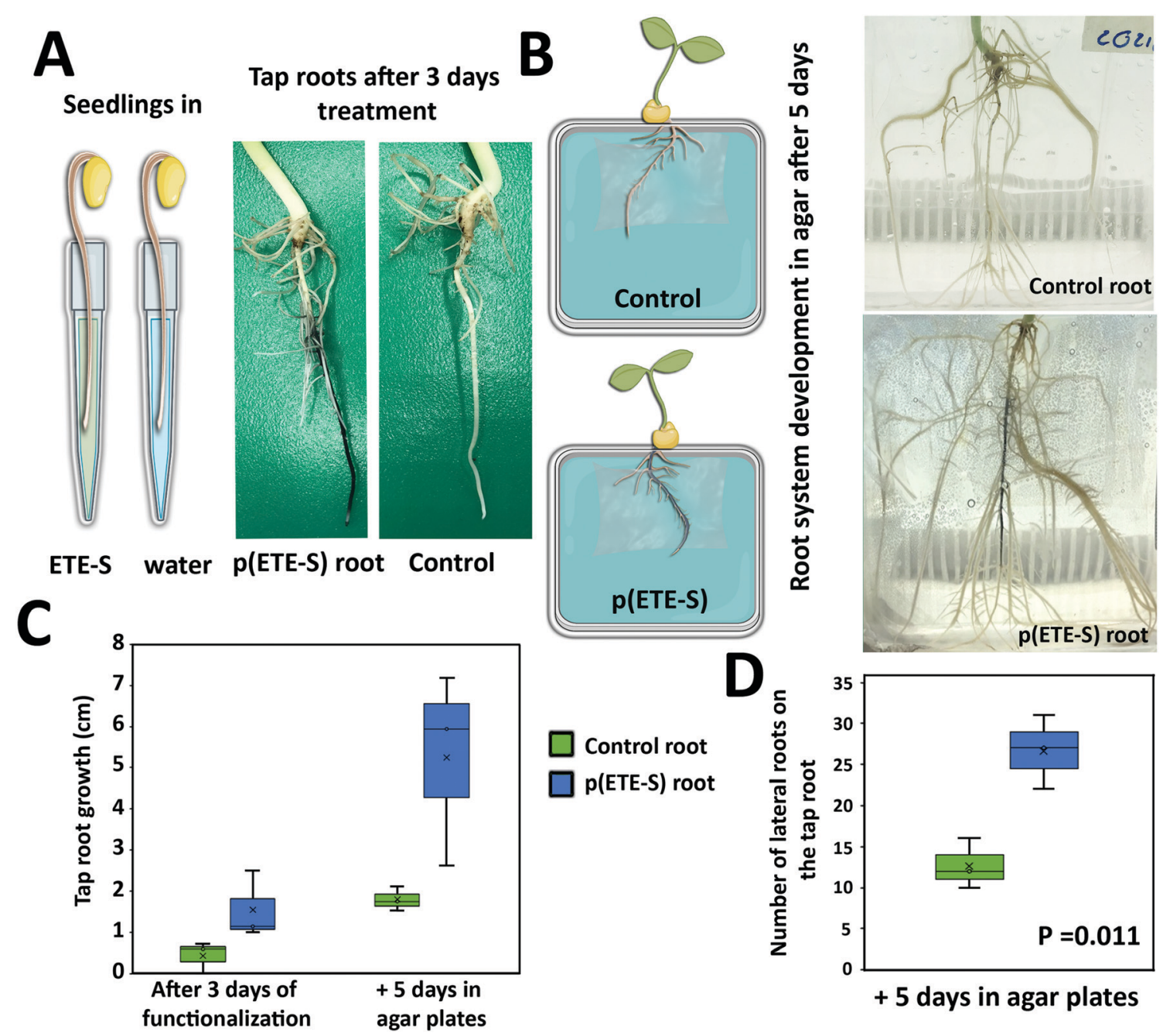

Fig. 5 Seedling development after ETE-S functionalization. (A) Seedlings were placed in ETE-S solution or water (control) for 3 days (created with BioRender.com). Photographs show the root system after treatment. (B) Control and $\mathrm{p}(\mathrm{ETE}-\mathrm{S}$ ) seedlings were then placed in agar plates and let to grow for 5 days as shown in the photographs (schematic created with BioRender.com). (C) Tap root growth in the control and p(ETE-S) plants right after functionalization and after 5 days of growth in agar plates. (D) Number of lateral roots emerging from tap root after 5 days of growth in agar plates for the control and $\mathrm{p}$ (ETE-S) plants. ( $n=3$ control, $n=3$ p(ETE-S) plants, $T$-test, $P<0.05$ ). 
for 5 days and we observed that p(ETE-S) functionalized tap roots grew more than the tap roots in the control plants. The trend was clear but not statistically significant due to large sample variability (Fig. 5C). Therefore, even though the root was covered in polymer, root growth was not inhibited but enhanced. Furthermore, the number of lateral roots emerging from the tap root increased significantly in $\mathrm{p}$ (ETE-S) roots after 5 days of growth, extending considerably the complexity of the functionalized root system compared to control plants (Fig. 5D). The enhancement of root growth and lateral root emergence can be the result of the adaptation and compensation of the plant to the polymer-coated tissue. It has been reported that modification of the mechanical properties of the cell walls via $\mathrm{Si}$ application increases primary root length and lateral root number. ${ }^{45}$ Plant cell wall macromolecules such as lignin, cellulose and pectin seem to template Si deposition in the form of silica even though the molecular mechanisms remain unclear. $^{46}$ In the case of ETE-S more biological studies are required to elucidate if ETE-S is altering the mechanical properties of the cell wall or if any other effect on the roots is responsible for the growth enhancement.

As a proof of concept, we also functionalized the whole root system of a plant and followed its growth for 1 month, Fig. 6 . We observed that the roots continued to grow and developed new lateral roots. The shoot not only grew bigger but also produced beans. Similar observations were made in the plants where 1 or 2 roots were functionalized for electrical conductivity measurements. Finally, in order to demonstrate that the polymerization of ETE-S is not specific to the bean plants root system we also functionalized roots of a pea plant. ETE-S polymerized along the pea plant roots forming a polymer coating (Fig. S9, ESI $\dagger$ ).

In conclusion, we demonstrated biohybrid plants with an electronic root system. ETE-S in vivo polymerizes, and the resulting polymer integrates with the epidermis of plant cells.
The $\mathrm{p}(\mathrm{ETE}-\mathrm{S})$ is structurally templated by the plant tissue, with enhanced pi-pi stacking resulting in a stable conducting coating. The conductivity of the $\mathrm{p}$ (ETE-S) roots reaches $10 \mathrm{~S} \mathrm{~cm}^{-1}$ and is not affected by the plant growth and development during the period of the study, 1 month. Functionalized seedlings developed a more complex root system than control plants indicating the ability of the plant to adapt to the hybrid state. As a proof of concept, we developed a root-supercapacitor with capacitance reaching $8 \mathrm{mF}$ and $0.6 \mathrm{~V}$ cut off voltage outperforming the devices previously integrated in the vascular tissue of plant cuttings. Our results overall show that the plant's root system is very promising for functionalization with electronic materials for several reasons. First the lack of cuticle enables the direct exposure of the cell wall biocatalytic machinery to oligomers that are then polymerized into the functional components of the tissue in a simple and scalable manner. Secondly the roots are readily accessible for external electrical contact required for addressing and readout. Finally, the biological functions of the root, from environmental responsiveness to exudation and symbiosis with microorganisms open a broad range of potential applications for biohybrid systems. In the future, we envision biohybrid plants for autonomous energy systems, underground adaptable sensors, and soft robotics.

\section{Methods}

\section{Plant growth}

Seeds of Phaseolus vulgaris were bought from Impecta Fröhandel and germinated in commercial plant starter cubes, Root Riot. Under a laminar flow hood, the cubes were moistened with DI water and the seeds were positioned in a small hole in the middle of the cube. Then, the scaffold was placed in a closed transparent plastic container and sealed with parafilm for five to

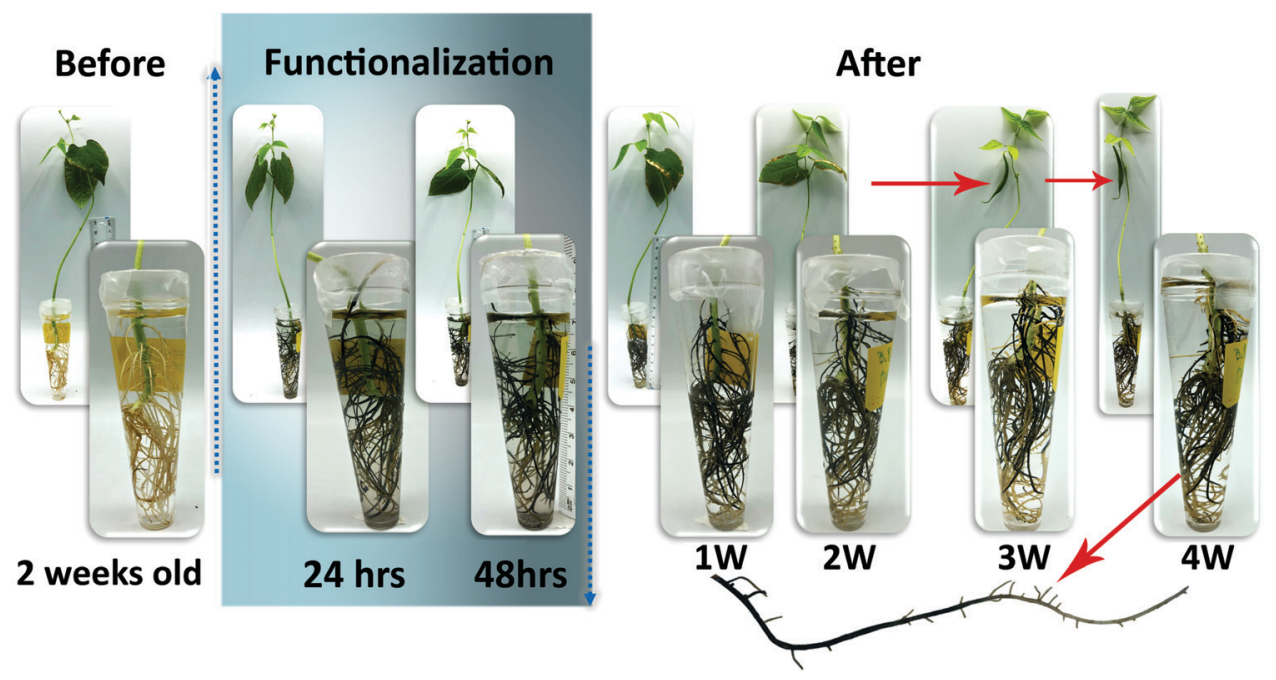

Fig. 6 Bean plant growth when the whole root system is functionalized with ETE-S. Photographs of the bean plant before, during and after functionalization with ETE-S. At week 3 bean pods are visible in the plant. The individual root close-up shows that new roots have grown after p(ETE-S) coating. 
seven days. The seeds were incubated in the dark at $20-22{ }^{\circ} \mathrm{C}$ until germination. After germination, seedlings were moved to containers filled with the nutrient solution $(0.5 \% \mathrm{v} / \mathrm{v}$ in tap water, Hyponex) and placed in a greenhouse under the following growth conditions: temperature $23-25{ }^{\circ} \mathrm{C}$, humidity $50-60 \%$, and 12 hours day with a light intensity in the range of 80-100 $\mu \mathrm{mol} \mathrm{m} \mathrm{m}^{-2} \mathrm{~s}^{-1}$.

\section{ETE-S synthesis}

ETE-S was synthetized accordingly to the literature. ${ }^{18}$ Briefly, a 2,5-dibromination with $\mathrm{N}$-bromosuccinimide on 3-thiopheneethanol gave the starting material for a Suzuki reaction using two equivalents of a 2-borolane-EDOT derivative. Then, a propane sultone ring-opening gives the sulfonate derivate.

\section{Plant root functionalization with ETE-S}

Individual roots. Roots from 2-week-old seedlings were functionalized using $1 \mathrm{mg} \mathrm{ml}^{-1}$ or $2 \mathrm{mg} \mathrm{ml}^{-1}$ freshly prepared ETE-S aqueous solution. Roots, about 10-15 mm long, were selected after optical inspection to ensure that no wounds were present. While being still attached to the plant, they were placed within an Eppendorf tube containing the ETE-S solution for 72 hours. The rest of the root system was kept in the nutrient solution $(0.5 \% \mathrm{v} / \mathrm{v}$ in tap water, Hyponex). After functionalization, roots were removed from the ETE-S solution and were placed in the nutrient solution until further characterization.

Whole root system. The whole root system of a bean plant that is two and a half weeks old was placed in the $0.2 \mathrm{mg} \mathrm{ml}^{-1}$ ETE-S solution in a $25 \mathrm{ml}$ volume glass container for three days. Afterwards, it was placed in a $50 \mathrm{ml}$ volume plastic container with tap water to let the plant grow. Photographs of the root system and the whole plant were taken every week for one month.

\section{Time lapse microscopy experiment and image processing}

A root from a young plant was immobilized in a reservoir filled with water under a microscope, while the other roots were placed in a commercial gel with nutrients (Seedhru. gel) to avoid dehydration (Fig. S2, ESI $\dagger$ ). An initial image was acquired to define the control frame that corresponds to $t=0$. Afterwards, the reservoir was emptied and filled with fresh ETE-S trimer solution of $1 \mathrm{mg} \mathrm{ml}^{-1}$ concentration while images were acquired periodically for $400 \mathrm{~min}$. During the first two and a half hours, images were taken every 30 seconds. Afterwards, images were taken every five minutes until reaching 399 minutes. We converted selected micrographs to gray scale where 0 corresponds to black and 255 to white color (Fig. S3, ESI $\dagger$ ). Within a defined region of interest (ROI), we then calculated the average grey value using Image-J and normalized it to the value at $t=0$.

\section{Microscopy}

Functionalized roots $\left(n=3\right.$ for $1 \mathrm{mg} \mathrm{ml}^{-1}$ and $n=2$ for $2 \mathrm{mg} \mathrm{ml}^{-1}$ ) were detached from the plant using a sterile scalpel and fixed with $4 \%$ paraformaldehyde (PFA) (w/v, dissolved in PBS $1 \times$ ) at $4{ }^{\circ} \mathrm{C}$ for $24-48 \mathrm{~h}$. At the beginning of the fixation, samples were incubated for $1 \mathrm{~h}$ under vacuum to enhance the penetration of the fixative. After the fixation, the PFA was discarded, and the samples were rinsed twice with PBS $1 \times$ and twice with MilliQ water to remove the remaining PFA. Before being further processed, roots were placed on a slide with enough PBS $1 \times$ to prevent them from drying out and the deposition of the polymerized ETE-S was analyzed on the root epidermis surface. Images of the surface of the root were taken using a Leica M205 FA stereomicroscope combined with a Leica DMC6200 camera and the PLANAPO $2.0 \times$ objective. To make the transversal and longitudinal sections, root samples were embedded in $4-5 \%$ agarose (w/v, dissolved in MilliQ water). For each root area the first half $\mathrm{cm}$ was used for longitudinal sections while the second half $\mathrm{cm}$ was used for transversal sections. Then, transversal and longitudinal sections, $25 \mu \mathrm{m}$ thick, were taken using a Leica VT1000 S vibratome (Speed 2:75 $\mu \mathrm{m} \mathrm{s}^{-1}$, Frequency 4:40 hz). Following sectioning, the sections were mounted in $50 \%$ glycerol solution and the slide was sealed using nail polish to ensure longer preservation. Images were taken using a Leica DMi 8 microscope combined with a Leica DFC7000 T camera and the $10 \times$ and $20 \times$ objectives.

\section{Electrical conductivity characterization}

For characterization, we developed a 3D printed holder with a central channel for the root and perpendicular channels for carbon fibers. The root, while attached to the plant, was placed in the central channel with deionized water to prevent dehydration. Two carbon fibers were placed perpendicular to the root separated by 5, 10, 15 and $20 \mathrm{~mm}$ and were used as contact electrodes for the roots. The carbon fibers were addressed via micromanipulators under the microscope with Au-plated tungsten probes $(50 \mu \mathrm{m})$ coated with carbon paste. IV measurements were performed at various lengths with voltage swept between -0.5 and $0.5 \mathrm{~V}$ at $0.62 \mathrm{mV} \mathrm{s}^{-1}$ scan rate using a Keithley K2600B instrument and a custom-made Lab-view program. Assuming an ideal resistor behavior, we plotted the resistance values versus length and performed a linear fit to extract the $R$ /length for the two ETE-S concentrations, with $n=3$ for each concentration in week one and week four after functionalization. At the end of the last measurement, transversal sections of the roots were done around the maturation zone to measure the thickness of the coating using a stereomicroscope. To minimize error for each sample we measured the diameter of the whole root section $\left(D_{1}\right)$ and then diameter of the non-coated area $\left(D_{2}\right)$ in 20 locations. Then the cross-section area of the conductor was calculated using $A=\pi\left(R_{1}{ }^{2}-R_{2}{ }^{2}\right)$, and then the conductivity was calculated using $\sigma=1 /(R \times A)$.

\section{Electrochemical characterization}

Cyclic voltammetry was performed in a three-electrode set-up consisting of the functionalized root as the working electrode, carbon felt ( $6 \mathrm{~cm}$ diameter, $2 \mathrm{~cm}$ thick) as the counter electrode, and $\mathrm{Ag} / \mathrm{AgCl}$ as the reference electrode. $\mathrm{CV}$ with scan rates between 5 and $20 \mathrm{mV} \mathrm{s}^{-1}$ and within $(-0.5,+0.5 \mathrm{~V})$ were 
performed in $0.01 \mathrm{M} \mathrm{KCl}$ electrolyte using a Garmy potentiostat 1010B.

\section{Root supercapacitor device fabrication and characterization}

The electrodes of a supercapacitor were defined by two functionalized roots. The spacer of the supercapacitor was defined by the surrounding $\mathrm{KCl} 0.01 \mathrm{M}$ electrolyte. Contact with the electrodes was made using carbon fibers as described in the conductivity measurements. The supercapacitor was characterized using $\mathrm{CV}$ and galvanostatic charging/discharging where the absolute value of charging currents was kept equal to the discharging one. Devices were switched from charging to discharging as soon as the set maximum voltage $(0.6 \mathrm{~V})$ was reached. A simple equivalent circuit of $\mathrm{R}$, $\mathrm{C}$ in series was used to fit the discharging response of the supercapacitor. The resistor represents the equivalent series resistance.

The device capacitance $C$ and the ESR were extracted using the following relations:

$C=I(\mathrm{~d} V / \mathrm{d} t)$ where $I$ is the applied current, and $\mathrm{d} V=\mathrm{d} t$ is the slope of the discharge curve as done in standardized characterization of supercapacitors (IEC 62576).

ESR $=\Delta V / 2 I$, where $I$ is the applied current and $\Delta V$ is the sudden voltage drop at the beginning of the discharging curve.

\section{ETE-S in vitro enzymatic polymerization}

Enzymatically synthesized p(ETE-S) was obtained by mixing 10 Units $\mathrm{ml}^{-1}$ of Horseradish peroxidase with $5 \mathrm{mM}$ of ETE-S, and $\mathrm{H}_{2} \mathrm{O}$. The solution was then continuously stirred for $5 \mathrm{~min}$ under vortex, providing the time for the total amount of ETE-S to be consumed. The resulting dispersion of the polymer was then drop casted on top of a Si substrate and let to dry overnight.

\section{X-ray scattering experiments}

Wide-angle X-ray scattering experiments at the transmission geometry and at the grazing incidence geometry (WAXS and GIWAXS, respectively) were performed at the NCD-SWEET beamline of the ALBA Synchrotron, located in Cerdanyola del Vallès, Spain. The wavelength of the X-rays, $\lambda$, was $0.9998 \AA$ $(12.4 \mathrm{keV})$, the sample-to-detector distance was $22.91 \mathrm{~cm}$ and, in case of the in vitro polymerized films, the angle of incidence, $\alpha_{i}$, was set at $0.16^{\circ}$. The diffracted intensity was recorded using a Rayonix LX255-HS detector, which consists of a pixel array of $1920 \times 5760(\mathrm{H} \times \mathrm{V})$ and a pixel size of $44 \times 44 \mu^{2}$. Data were normalized by the incident photon flux and the acquisition time. Flat field, polarization, solid angle and efficiency corrections were additionally applied to the 2D GIWAXS images. The scattering vector $q$ was defined with respect to the center of the incident beam and has a magnitude of $q=(4 \pi / \lambda) \sin (\theta)$, where $2 \theta$ is the Bragg reflection angle. An azimuthal integration has been performed on the 2D images to obtain the corresponding 1D scattering patterns. 1D scattering patterns are presented herein after background subtraction.

\section{Plant growth assay}

Bean seeds were germinated as described in the "Plant growth" section. After germination the scaffold was removed. The tap root of three seedlings was kept in a reservoir with fresh ETE-S solution ( $1 \mathrm{mg} \mathrm{ml}^{-1}$ ETE-S), while the rest of the root system was kept in tap water. For the control, the tap root of three seedlings was placed in a reservoir with deionized water, and the rest of the root system was kept in tap water. After three days of functionalization, the root system was washed with Di-W. The seedlings were transferred to agar plates: Petri dishes with agar $\left(10 \mathrm{~g} \mathrm{l}^{-1}\right)$ and 1/2 MS medium were prepared and perforated so that the root system grows under closed conditions while the stem grows under ambient conditions. The seedlings were placed between the treated cellophane sheets, and the Petri dishes were well sealed with parafilm. Photographs of the root system were taken every day to monitor its growth.

\section{Author contributions}

E. S. conceived the project, designed, and supervised the research. D. P. performed most experiments and data analysis including functionalization of roots, all electrical and electrochemical measurements, microscopy, and plant growth assay. Y. D. prepared and performed microscopy of the fixed samples and assisted in plant biology protocols. G. D. performed UV-Vis absorption spectroscopy in untreated and treated freeze-dried samples and prepared samples for X-ray analysis. D. M. synthesized ETE-S. E. P. performed X-ray scattering experiments and analysis with the help of ESol. M. B., T. N., E. C. and G. H. contributed to the supervision. E. S. wrote the paper with input from D. P., Y. D., E. P. and comments from all authors.

\section{Conflicts of interest}

There are no conflicts of interest to declare.

\section{Acknowledgements}

The authors wish to thank Roger Gabrielsson (Linköping University) for the synthesis of ETE-S at the early stages of the study, Jesper Edberg (RISE, Sweden) and Mehmet Girayhan Say (Linköping University) for fruitful insights on supercapacitor development and Johannes Gladisch (Linköping University) for help with the 3D-printed conductivity holder. GIWAXS experiments were performed at BL11-NCD-SWEET beamline at ALBA Synchrotron with the collaboration of ALBA staff. Schematics in Fig. 2A, 3A, 4A, 4C and 5A, B, S2 and S6A were created with biorender.com. This work was supported by the European Union's Horizon 2020 research and innovation program under grant agreement No. 800926 (FET-OPEN-HyPhOE) and by the Swedish Research Council (VR-2017-04910). Additional funding was provided by European Union's Horizon 2020 Marie Skłodowska-Curie fellowship under grant agreement No. 838171 (TEXTHIOL), the Knut and Alice Wallenberg Foundation, 
the Wallenberg Wood Science Center (KAW 2018.0452), the Swedish Government Strategic Research Area in Materials Science on Advanced Functional Materials at Linköping University (Faculty Grant SFO-Mat-LiU No. 2009-00971) and the European Research Council (ERC) project e-NeuroPharma 834677.

\section{References}

1 P. Fratzl, J. R. Soc., Interface, 2007, 4, 637-642.

2 Y. Liu, K. He, G. Chen, W. R. Leow and X. Chen, Chem. Rev., 2017, 117, 12893-12941.

3 T. T. S. Lew, V. B. Koman, P. Gordiichuk, M. Park and M. S. Strano, Adv. Mater. Technol., 2020, 5, 1900657.

4 E. Stavrinidou, R. Gabrielsson, E. Gomez, X. Crispin, O. Nilsson, D. T. Simon and M. Berggren, Sci. Adv., 2015, 1, e1501136.

5 F. Meder, M. Thielen, A. Mondini, T. Speck and B. Mazzolai, Energy Technol., 2020, 8, 2000236.

6 M. H. Wong, R. P. Misra, J. P. Giraldo, S. Y. Kwak, Y. Son, M. P. Landry, J. W. Swan, D. Blankschtein and M. S. Strano, Nano Lett., 2016, 16, 1161-1172.

7 T. T. S. Lew, M. H. Wong, S. Y. Kwak, R. Sinclair, V. B. Koman and M. S. Strano, Small, 2018, 14, 2000236.

8 M. H. Wong, J. P. Giraldo, S. Y. Kwak, V. B. Koman, R. Sinclair, T. T. S. Lew, G. Bisker, P. Liu and M. S. Strano, Nat. Mater., 2017, 16, 264-272.

9 T. T. S. Lew, M. Park, J. Cui and M. S. Strano, Adv. Mater., 2021, 33, 2005683.

10 S. Y. Kwak, J. P. Giraldo, M. H. Wong, V. B. Koman, T. T. S. Lew, J. Ell, M. C. Weidman, R. M. Sinclair, M. P. Landry, W. A. Tisdale and M. S. Strano, Nano Lett., 2017, 17, 7951-7961.

11 E. Stavrinidou, R. Gabrielsson, K. P. R. Nilsson, S. K. Singh, J. F. Franco-Gonzalez, A. V. Volkov, M. P. Jonsson, A. Grimoldi, M. Elgland, I. V. Zozoulenko, D. T. Simon and M. Berggren, Proc. Natl. Acad. Sci. U. S. A., 2017, 114, 2807-2812.

12 B. D. Paulsen, K. Tybrandt, E. Stavrinidou and J. Rivnay, Nat. Mater., 2020, 19, 13-26.

13 E. Stavrinidou, P. Leleux, H. Rajaona, D. Khodagholy, J. Rivnay, M. Lindau, S. Sanaur and G. G. Malliaras, Adv. Mater., 2013, 25, 4488-4493.

14 R. B. Bazaco, R. Gómez, C. Seoane, P. Bäuerle and J. L. Segura, Tetrahedron Lett., 2009, 50, 4154-4157.

15 D. Mantione, I. del Agua, A. Sanchez-Sanchez and D. Mecerreyes, Polymers, 2017, 9, 354.

16 T. Galán, B. Prieto-Simón, M. Alvira, R. Eritja, G. Götz, P. Bäuerle and J. Samitier, Biosens. Bioelectron., 2015, 74, 751-756.

17 G. Dufil, D. Parker, J. Y. Gerasimov, T. Q. Nguyen, M. Berggren and E. Stavrinidou, J. Mater. Chem. B, 2020, 8, 4221-4227.

18 D. Mantione, E. Istif, G. Dufil, L. Vallan, D. Parker, C. Brochon, E. Cloutet, G. Hadziioannou, M. Berggren, E. Stavrinidou and E. Pavlopoulou, ACS Appl. Electron. Mater., 2020, 2, 4065-4071.

19 S. H. Su, N. M. Gibbs, A. L. Jancewicz and P. H. Masson, Curr. Biol., 2017, 27, R964-R972.

20 B. K. Ham, J. Chen, Y. Yan and W. J. Lucas, Curr. Opin. Biotechnol, 2018, 49, 1-9.
21 J. Lamers, T. Van Der Meer and C. Testerink, Plant Physiol., 2020, 182, 1624-1635.

22 S. A. Rolfe, J. Griffiths and J. Ton, Curr. Opin. Microbiol., 2019, 49, 73-82.

23 A. V. Volkov, K. Wijeratne, E. Mitraka, U. Ail, D. Zhao, K. Tybrandt, J. W. Andreasen, M. Berggren, X. Crispin and I. V. Zozoulenko, Adv. Funct. Mater., 2017, 27, 1700329.

24 V. B. Ivanov and J. G. Dubrovsky, Trends Plant Sci., 2013, 18, 237-243.

25 A. Barrada, M. H. Montané, C. Robaglia and B. Menand, Int. J. Mol. Sci., 2015, 16, 19671-19697.

26 R. De-Jesús-García, U. Rosas and J. G. Dubrovsky, Funct. Plant Biol., 2020, 47, 383-397.

27 J. Namyslov, Z. Bauriedlová, J. Janoušková, A. Soukup and E. Tylová, Plants, 2020, 9, 201.

28 A. Berhin, D. de Bellis, R. B. Franke, R. A. Buono, M. K. Nowack and C. Nawrath, Cell, 2019, 176, 1367-1378.e8. 29 R. P. Kumpf and M. K. Nowack, J. Exp. Bot., 2015, 66, 5651-5662. 30 P. W. Barlow, J. Plant Growth Regul., 2002, 21, 261-286.

31 C. Durand, M. Vicré-Gibouin, M. L. Follet-Gueye, L. Duponchel, M. Moreau, P. Lerouge and A. Driouich, Plant Physiol., 2009, 150, 1411-1421.

32 M. Cai, N. Wang, C. Xing, F. Wang, K. Wu and X. Du, Environ. Sci. Pollut. Res., 2013, 20, 8924-8933.

33 N. Kumar and A. S. Iyer-Pascuzzi, Plants, 2020, 9, 308.

34 G. Dijk, A. L. Rutz and G. G. Malliaras, Adv. Mater. Technol., 2020, 5, 1900662.

35 A. D. French, Cellulose, 2014, 21, 885-896.

36 K. E. Aasmundtveit, E. J. Samuelsen, L. A. A. Pettersson, O. Inganäs, T. Johansson and R. Feidenhans'l, Synth. Met., 1999, 101, 561-564.

37 J. F. Franco-Gonzalez, E. Pavlopoulou, E. Stavrinidou, R. Gabrielsson, D. T. Simon, M. Berggren and I. V. Zozoulenko, Nanoscale, 2017, 9, 13717-13724.

38 A. V. Volkov, S. K. Singh, E. Stavrinidou, R. Gabrielsson, J. F. Franco-Gonzalez, A. Cruce, W. M. Chen, D. T. Simon, M. Berggren and I. V. Zozoulenko, Adv. Electron. Mater., 2017, 3, 1700096.

39 K. Tybrandt, I. V. Zozoulenko and M. Berggren, Sci. Adv., 2017, 3, eaao3659.

40 A. Malti, J. Edberg, H. Granberg, Z. U. Khan, J. W. Andreasen, X. Liu, D. Zhao, H. Zhang, Y. Yao, J. W. Brill, I. Engquist, M. Fahlman, L. Wågberg, X. Crispin and M. Berggren, Adv. Sci., 2016, 3, 1500305.

41 M. G. Say, R. Brooke, J. Edberg, A. Grimoldi, D. Belaineh, I. Engquist and M. Berggren, npj Flexible Electron., 2020, 4, 14.

42 H. Wang, Y. Diao, Y. Lu, H. Yang, Q. Zhou, K. Chrulski and J. M. D’Arcy, Nat. Commun., 2020, 11, 3882.

43 R. Reece, C. Lekakou and P. A. Smith, ACS Appl. Mater. Interfaces, 2020, 12, 25683-25692.

44 M. O. Bamgbopa, D. Belaineh, D. A. Mengistie, J. Edberg, I. Engquist, M. Berggren and K. Tybrandt, J. Mater. Chem. A, 2021, 9, 2184-2194.

45 P. Tripathi, S. Subedi, A. L. Khan, Y.-S. Chung and Y. Kim, Plants, 2021, 10, 885.

46 G. Guerriero, J. F. Hausman and S. Legay, Front. Plant Sci., 2016, 7, 463. 